\title{
Roles of larval sea urchin spicule SM50 domains in organic matrix self-assembly and calcium carbonate mineralization
}

\author{
Ashit Rao $^{\mathrm{a}, \mathrm{c}}$, Jong Seto ${ }^{\mathrm{a}, *}$, John K. Berg ${ }^{\mathrm{a}}$, Stefan G. Kreft ${ }^{\mathrm{b}, \mathrm{c}}$, Martin Scheffner ${ }^{\mathrm{b}, \mathrm{c}}$, Helmut Cölfen ${ }^{\mathrm{a}, \mathrm{c}}$ \\ a Physical Chemistry, Department of Chemistry, University of Konstanz, Universitätsstraße 10, PO Box 714, D-78457 Konstanz, Germany \\ ${ }^{\mathrm{b}}$ Cellular Biochemistry, Department of Biology, University of Konstanz, Universitätsstraße 10, PO Box 714, D-78457 Konstanz, Germany \\ ${ }^{\mathrm{C}}$ Konstanz Research School of Chemical Biology, University of Konstanz, Universitätsstraße 10, PO Box 714, D-78457 Konstanz, Germany
}

Keywords:

SM50

SM50 structural domains

Spicule matrix proteins

Intrinsic disorder

Matrix assembly

Amorphous calcium carbonate

Biomineralization

\begin{abstract}
A B S T R A C T
The larval spicule matrix protein SM50 is the most abundant occluded matrix protein present in the min eralized larval sea urchin spicule. Recent evidence implicates SM50 in the stabilization of amorphous cal cium carbonate (ACC). Here, we investigate the molecular interactions of $\mathrm{SM}_{50}$ and $\mathrm{CaCO}_{3}$ by investigating the function of three major domains of SM50 as small ubiquitin like modifier (SUMO) fusion proteins a $C$ type lectin domain (CTL), a glycine rich region (GRR) and a proline rich region (PRR). Under various mineralization conditions, we find that SUMO CTL is monomeric and influences $\mathrm{CaCO}_{3}$ mineralization, SUMO GRR aggregates into large protein superstructures and SUMO PRR modifies the early $\mathrm{CaCO}_{3}$ mineralization stages as well as growth. The combination of these mineralization and self assembly properties of the major domains synergistically enable the full length SM50 to fulfill func tions of constructing the organic spicule matrix as well as performing necessary mineralization activities such as $\mathrm{Ca}^{2+}$ ion recruitment and organization to allow for proper growth and development of the min eralized larval sea urchin spicule.
\end{abstract}

\section{Introduction}

An underlying organic matrix can be found in all biominerals ranging from silica to calcium as well as iron carbonates, just to name a few varieties (Falini et al., 1996; Metzler et al., 2010;Wang and Li, 2002; Gur et al., 2013; Sel et al., 2012). And in each case, the organic component varies widely from one mineral to another, as well as within the mineral system, from species to species. The role of this organic component in biominerals has been explored by many groups (Belcher et al., 1996; Fratzl and Weinkamer, 2007; Hao et al., 2007; Weiner and Wagner, 1998; Amos et al., 2011; Evans, 2012; Fang et al., 2011; Metzler et al., 2010). These roles include functional requirements such as enhancement of mechan ical performance and materials properties elasticity, strength, toughness (Fratzl and Weinkamer, 2007; Weiner and Wagner, 1998). In the endeavor to understand what makes these materials 'strong' and 'high performance', several groups have looked to the use of in situ mutagenesis in these mineral systems as well as

Abbreviations: SM50, spicule matrix protein 50; CTL, C-type lectin; GRR, gly-rich region; PRR, pro-rich region; SUMO, small ubiquitin-like modifier; IDP, intrinsically disorder protein.

* Corresponding author. Address: Department of Chemistry, University of Konstanz, PO Box 714, Universitätstraße 10, D-78457 Konstanz, Germany. Fax: +49 7531883139 .

E-mail addresses: jong.seto@uni-konstanz.de, jongseto@ocf.berkeley.edu (J. Seto). creating in vitro studies that mimic the conditions in which miner alization occurs (Amos et al., 2011; Ndao et al., 2010). Some have ascertained the roles of these organic components to include the templating for the respective mineral components, stabilization of amorphous mineral phases, as well as inhibition of mineraliza tion (Falini et al., 1996; Foo et al., 2004; Gong et al., 2012; Metzler et al., 2010; Radha et al., 2010; Wang and Li, 2002) In complement ing these studies, we investigate the well established developmen tal model system of the larval sea urchin Strongylocentrotus purpuratus and study the mineral organic interactions of the spicule matrix protein (SMP) SM50 found in larval spicule formation.

The diversity of the organic matrix found in the larval sea urch in spicule is surprising. Over 200 proteins are found in the larval spicule (Mann et al., 2010), which make up less than $0.1 \% \mathrm{w} / \mathrm{v}$ of the entire spicule (Wilt and Killian, 2008). The interest in examin ing these proteins in the sea urchin spicule can be observed from the single crystalline properties of the spicule, while the super structure of a single spicule is observed to be smooth and curved, without providing evidence of step edges nor clues of its single crystalline properties. Politi et al. (2007) showed that adult sea urchins have the ability to regenerate their spines through an amorphous mineral precursor phase. Overgrowth experiments of the larval spicule in supersaturated solutions of calcium carbonate, reveal the preferential $\mathrm{C}$ axis alignment of the individual calcite 
crystals that form the larval spicule (Beniash et al., 1997). In both of these studies, observations of a component which can stabilize amorphous mineral phases as well as organize mineral at the nanoscale level requirements which lead finally to the formation of a mesocrystalline structure of both calcite and amorphous cal cium carbonate even in the adult spine (Seto et al., 2012). Wilt and coworkers have examined the organic matrix and revealed two large families of matrix proteins that are found during the first occurrence of mineral in the spicular mineralization space (Wilt and Killian, 2008; Katoh Fukui et al., 1991; Sucov et al., 1987). These protein families, SM30 and SM50, have common motifs, more specifically, a C type lectin domain, as well as regions with long amino acid repeats. Specifically, these long amino acid repeats have recently been implicated in various functions ranging from mediators of multiple binding interactions as well as chaperones in signaling (Uversky, 2002; Uversky et al., 2000; Uversky et al., 2008).

Specifically, the SM50 family is the most abundant occluded SMP found in the mineralized spicule. The primary sequences of both SM50 and SM30 families consist of homologous sequence motifs, mainly $C$ type lectin domains and intrinsic disordered re peat domains (Livingston et al., 2006). These $C$ type lectin domains have been implicated in many activities including complex macro molecule assembly, carbohydrate complexation, as well as recep tor signaling processes. Interestingly, $\mathrm{C}$ type lectin domains in the genus Strongylocentrotus have been implicated in immunity re sponses and suggest that these domains have been co opted for biomineralization purposes through evolution (Gross et al., 1999; Silva, 2000; Smith, 2005). As is often the case, the $C$ type lectins discussed here require proper amounts of $\mathrm{Ca}^{2+}$ ions to fold properly for correct structural conformations (Diao and Tajkhorshid, 2008; Fuerst et al., 2013). In contrast, numerous intrinsically disordered repeat (IDP) domains are found in the SMPs and have no such necessity of conformation for proper function. IDP domains are natively structurally flexible due to their composition of random repeats of various single amino acids, often charged in nature including aspartic acid (D) (Ndao et al., 2010) and glutamic acid (E) (Nonoyama et al., 2012), non charged in the case of serine (Ser), leucine (Leu), asparagine (Asp), or just glycine (Gly) and pro line (Pro). The relevance of these IDPs have been underestimated and recently, their impact in understanding the regulation and pro cessing of the proteome has been found to be essential (Uversky, 2002; Uversky et al., 2000; Kalmar et al., 2012). Functionally, IDPs have been connected to mis folding and signaling of proteins that are involved in cardiovascular and neurodegenerative diseases (Uversky et al., 2008). Our study will focus on the major structural domains found in SM50 as well as IDP domains. in order to delin eate their contributions to the proper function of the full length SM50 in the biomineralization of the larval sea urchin spicule.

We describe here the expression of major SM50 domains (C type lectin, glycine rich repeat, and proline rich repeat do mains) as small ubiquitin like modifier (SUMO) fusion proteins. In order to better understand the function of the full length SM50 in the biomineralization of the larval sea urchin spicule, we investigate the solution behaviors as well as the effects on the early stages of mineralization by vapor diffusion mediated growth of calcium carbonate of the major domains of SM50 as SUMO fusion proteins.

\section{Materials and methods}

\subsection{Cloning and protein purification}

Phusion Hi Fidelity Taq polymerase, T4 DNA ligase, restriction enzymes (New England Biolabs, Ipswich, MA, USA) and NTA Aga rose (Qiagen $\mathrm{GmbH}$, Hilden, Germany) were used for cloning and protein purification. L Arginine (reagent grade, $\geqslant 98 \%$ ) was pur chased from Sigma Aldrich.

\subsection{Mineralization experiments}

Calcium chloride (Fluka, $1 \mathrm{M}$ volumetric solution), sodium hydroxide (Alfa Aesar, 0.01 M standard solution), hydrochloric acid (Merck, $1 \mathrm{M}$ standard solution), sodium carbonate (Aldrich, anhy drous, A.C.S grade), sodium bicarbonate (Riedel de Haën, A.C.S) were used for gas diffusion and titration experiments. For potenti ometric titration measurements, a carbonate buffer composed of a mixture of $10 \mathrm{mM}$ sodium carbonate and $10 \mathrm{mM}$ sodium bicarbon ate mixed such that the $\mathrm{pH}=9.75$ was used.

\subsection{Bioinformatics analysis}

The prediction of protein disorder in SM50 (S. purpuratus, NCBI accession No. NM_214610.2) was accomplished by using DISOPRED, IUPRED and RONN algorithms (Dosztányi et al., 2005; Wang et al., 2009; Yang et al., 2005). And the biochemical proper ties such as isoelectric point and amino acid composition were calculated using PROTPARAM (Gasteiger et al., 2005). The putative domains for proteins were predicted using the SMART server (Schultz et al., 1998). SignalP4.1 was used to identify the signal peptide sequences (Petersen et al., 2011).

\subsection{Cloning and protein expression}

Based on the results of disorder prediction, three regions were identified, namely a $13.6 \mathrm{kDa} \mathrm{C}$ type lectin domain (CTL), a $27.2 \mathrm{kDa}$ glycine rich region (GRR) and a $3.9 \mathrm{kDa}$ proline rich region (PRR). These domains were intracellularly expressed as 6XHis SUMO fusion products using Escherichia coli. These are appropri ately referred to SUMO CTL, SUMO GRR and SUMO PRR, respec tively. Cloning of SM50 cDNA templates was performed in the Center for Regulatory Genomics, Beckman Institute and the Eric Davidson Lab, Division of Biology at Caltech. The pET24a backbone based plasmid for expression of SUMO fusion proteins was provided by Prof. Elke Deuerling (Department of Biology, Univer sity of Konstanz, Konstanz, Germany). Primers were designed as per the gene sequence of SM50 (NM_214610.2) using OligoExplor er 1.5 and OligoAnalyzer 1.5. The restriction sites for enzymes Bsal and Xhol were used in the forward and reverse primers, respec tively (Table 1). Initial constructs were made in E. coli DH5a. Stan dard molecular biology procedures were followed (Sambrook et al., 1989). The transformants were selected by plating on Luria agar ampicillin plates. The sequences of the constructs obtained were verified by capillary sequencing (GATC Biotech GmbH, Konstanz, Germany). The expression plasmids were transformed into compe tent E. coli BL21 CodonPlusRIL (Stratagene, Agilent Technologies Inc., Santa Clara, USA) cells and grown in Luria broth supplemented with ampicillin $(100 \mu \mathrm{g} / \mathrm{mL})$ and chloramphenicol $(35 \mu \mathrm{g} / \mathrm{mL})$. After attaining an absorbance of 0.6 O.D., induction of cell culture was done by using isopropyl $\beta$ D thiogalactopyranoside (IPTG, $0.5 \mathrm{mM})$ at $20^{\circ} \mathrm{C}$.

Table 1

Primers used for cloning of SM50 fragments. Restriction sites BsaI and XhoI are indicated in italics.

\begin{tabular}{ll}
\hline Primer name & Sequence \\
\hline FP-CTL & CCAGTGGGTCTCAGGTGGTACGGGTCAAGAC \\
RP-CTL & CCAGCTCGAGTCAGGGCCAGCTACG \\
FP-GRR & CCAGTGGGTCTCAGGTGGTGTCAACCCTCAGAACCCCAT \\
RP-GRR & CCAGCTCGAGTCATTGCTGGCCACCCAT \\
FP-PRR & CCAGTGGGTCTCAGGTGGTATGGGTGGCCAGCAA \\
FP-PRR & CCAGCTCGAGTCACTCTTGAAGCATACG \\
\hline
\end{tabular}




\subsection{Protein purification}

In the purification of both SUMO CTL and SUMO PRR, cell lysis was achieved by lysozyme treatment in HEPES/sodium chloride $(\mathrm{NaCl}) / \beta$ mercaptoethanol ( $\beta \mathrm{ME}$ ) buffer containing HEPES $(20 \mathrm{mM}), \mathrm{NaCl}(50 \mathrm{mM})$ and $\beta \mathrm{ME}(10 \mathrm{mM})$. The lysis buffer also contained pepstatin $\mathrm{A}(10 \mathrm{pg} / \mathrm{ml})$ and phenylmethylsulfonyl fluo ride $(0.5 \mathrm{mM})$ to inhibit proteolysis. The lysate was centrifuged at $16,000 \mathrm{rpm}(30,000 \mathrm{~g})$ for $30 \mathrm{~min}$ and the supernatant was loaded on a $\mathrm{Ni}^{2+}$ charged NTA (nitrilotriacetic acid) agarose column for immobilized metal affinity chromatography (IMAC). After an initial wash with $0.5 \mathrm{mM}$ imidazole, the protein of interest was eluted by using $20 \mathrm{mM}$ imidazole prepared in $\mathrm{HEPES} / \mathrm{NaCl} / \beta \mathrm{ME}$ buffer. Final purification was accomplished by size exclusion chromatography using a Superdex 75 column (HiLoad 16/60, Amersham Biosci ences, Pittsburg PA USA) on an Akta FPLC system.

The purification of SUMO GRR was performed from the lysate pellet. Initially, the pellet was dispersed in Triton X PBS (phos phate buffered saline) by sonication and the mixture was centri fuged at $16,000 \mathrm{rpm}(30,000 \mathrm{~g})$ for $20 \mathrm{~min}$. This procedure was repeated three times with the pellet to remove residual soluble proteins. The resulting pellet was dispersed in $\operatorname{Arg}(0.5 \mathrm{M})$ solution and incubated for $2 \mathrm{~h}$ at $4{ }^{\circ} \mathrm{C}$. Arg is known to improve protein solubility and inhibit protein aggregation (Golovanov et al., 2004; Tsumoto et al., 2004). The protein mixture was then centrifuged at $5000 \mathrm{rpm}(3000 \mathrm{~g})$ for $15 \mathrm{~min}$ and the solubilized protein was further purified by IMAC as described above. The elution buffer contained imidazole dissolved in $\operatorname{Arg}(0.5 \mathrm{M})$. The fraction contain ing the protein of interest was dialyzed against carbonate buffer ( $50 \mathrm{mM}, \mathrm{pH} 9.75$ ) for $16 \mathrm{~h}$ at $4^{\circ} \mathrm{C}$.

Protein estimation was performed by using the Bradford assay (Bradford, 1976). SDS polyacrylamide gel electrophoresis (SDS PAGE) of the protein fractions were performed using $14 \%$ acrylamide gels followed by staining with Coomassie Blue. The protein samples were desalted and concentrated by using 3000 MWCO Vivaspin centrifugal concentrators (Sartorius Stedim Biotech $\mathrm{GmbH}$, Göttingen, Germany). This was followed by solvent exchange by prolonged dialysis in either Milli Q (EMD Millipore Inc., Billerica, MA USA) water or carbonate buffer $(10 \mathrm{mM}, \mathrm{pH}$ 9.75). These protein samples in water were used for gas diffusion assays and those prepared in carbonate buffer were used for circu lar dichroism, dynamic light scattering and titration studies.

During purification, SUMO CTL and SUMO PRR were soluble and were purified by conventional IMAC and SEC steps (SI Fig. 1). Whereas, SUMO GRR was initially insoluble; however, in the pres ence of $\operatorname{Arg}(0.5 \mathrm{M})$, it displayed improved solubility. A proposed mechanism for Arg induced solubility is the binding of the amino acid methylene groups to hydrophobic surfaces on the protein. This results in masking the exposed hydrophobic surfaces and inhibiting protein aggregation (Cantaert et al., 2012). It is reason able that similar hydrophobic interactions exist between the glycine rich regions of SM50 monomers resulting in the aggrega tion and poor solubility of the native protein. After purification, the SDS PAGE profiles of the proteins displayed single bands at the expected molecular masses (Fig 1C). Bands were observed at approximately 26,41 and $19 \mathrm{kDa}$ for the SUMO CTL, SUMO GRR and SUMO PRR samples, respectively.

\subsection{Vapor/gas diffusion}

Calcium carbonate $\left(\mathrm{CaCO}_{3}\right)$ was precipitated from $0.2 \mathrm{~mL}$ drop lets of mixtures in 96 microwell plates; containing calcium chloride $\left(\mathrm{CaCl}_{2}\right)$ and protein $(0.01 \mathrm{mg}$ and $0.1 \mathrm{mg})$ using a gas diffusion set up. The droplets were exposed to $\mathrm{CO}_{2}$ generated by decomposition of ammonium carbonate $\left(\left(\mathrm{NH}_{4}\right)_{2} \mathrm{CO}_{3}\right)$ in a sealed desiccator. After $48 \mathrm{~h}$ of incubation, the calcium carbonate parti cles were analyzed by a desktop SEM (Hitachi TM 3000 SEM, Hitachi High Technologies Europe $\mathrm{GmbH}$, Krefeld, Germany) equipped with an energy dispersive detector (Xcite, Bruker AXS $\mathrm{GmbH}$, Berlin, Germany). During the gas diffusion experiments, the initial and final pH were 6.0 and 9.6, respectively.

\subsection{Dynamic light scattering}

Dynamic light scattering (DLS) experiments were performed with a custom built setup equipped with a goniometer, atempera ture control ( $0.05 \mathrm{~K}$ step control), an attached single photon detector ALV 6000/E, and a multiple tau digital correlator ALV 5000/FAST from ALV (ALV GmbH, Langen, Germany) as described in previous investgations (Cölfen, 2001). The protein solutions with different concentrations of calcium chloride were syringe filtered through $0.2 \mu \mathrm{m}$ pore size membrane filters (Whatman $\mathrm{GmbH}$, Dassel, Germany) and their particle size distributions were determined.

\subsection{Analytical ultracentrifugation}

Sedimentation velocity experiments were performed using a Beckman XL I ultracentrifuge (Beckman Coulter Inc., Palo Alto, CA USA). The moving boundary was monitored by repetitive radial scanning at $280 \mathrm{~nm}$ using a UV absorption optical system. The sed imentation velocity datasets were analyzedusing the software pro gram SEDFIT (P. Schuck, NIH, Bethesda, Md USA) to generate sedimentation coefficient and molar mass distributions (Schuck, 2000). In addition, 2 dimensional spectrum analysis (2 DSA, Monte Carlo) with 20 iterations and grid resolution of 3600 was performed by using the Ultrascan III software (B. Demeler, UltraScan Version 3.0,University of Texas Health Science Center at San Antonio, Department of Biochemistry) (Brookes et al., 2010). The solvent density, solvent viscosity and protein partial specific volumes were also calculated from the amino acid respec tive solvent composition with Ultrascan. Axial ratios of prolate

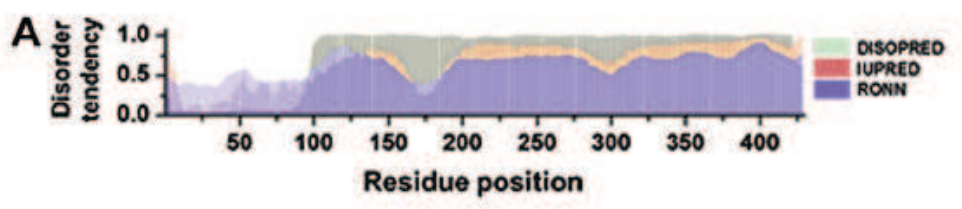

B
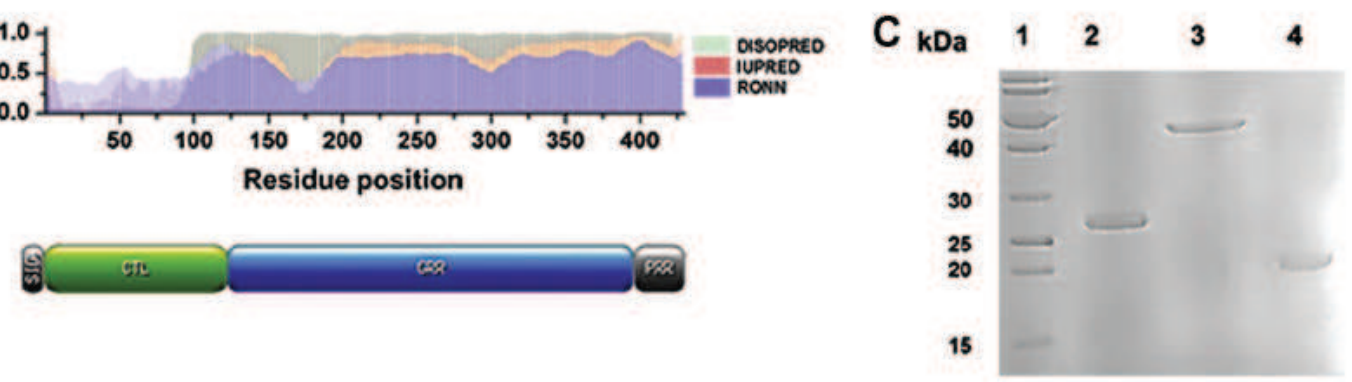

Fig.1. Primary and secondary structures of the domains in SM50. (A) Local disorder in SM50 predicted using DISOPRED (green), IUPRED (red) and RONN (blue) algorithms. (B) Schematic representation of the SM50 domains: secretion signal (1-17), C-type lectin domain (18-138, green), glycine rich region (139-410, blue) and proline rich region (411-440, grey).(C) Representative SDS-PAGE profile of purified proteins: Lane 1 standard molecular weight marker Lane 2 SUMO-CTL Lane 3 SUMO-GRR and Lane 4 SUMOPRR proteins. 
ellipsoids were predicted for given frictional ratios $f / f_{0}$ using the simulation option of Ultrascan.

\subsection{Transmission electron microscopy}

For sample preparation, an aliquot $(5 \mu \mathrm{L})$ of the protein solution was spotted on a TEM grid (Au, Formvar coated; Ted Pella, Inc., Redding, CA USA). Any excess liquid was blotted off and the grid was allowed to air dry for $12 \mathrm{~h}$. TEM imaging was performed using a Libra 120 (Zeiss SMT GmbH, Oberkochen, Germany) transmission electron microscope at $120 \mathrm{kV}$ with a beam current of $4 \mu \mathrm{A}$. TEM micrographs were analyzed with the Olympus Soft Imaging Viewer (Olympus Soft Imaging Solutions $\mathrm{GmbH}$, Muenster, Germany).

\subsection{Circular dichroism}

Circular dichroism (CD) experiments were performed on a Jasco J 715 Spectropolarimeter with a Peltier temperature control unit (Jasco International Co. Ltd., Tokyo, Japan) and using $1 \mathrm{~cm}$ quartz cuvettes. The spectra were recorded at $0.5 \mathrm{~nm}$ intervals between 190 and $240 \mathrm{~nm}$ at $20^{\circ} \mathrm{C}$, at $20 \mathrm{~nm} / \mathrm{s}$ scan rates. The secondary structure conformations were predicted from the measured spec tra with the application K2D3 (Greenfield, 2006; Louis Jeune et al., 2012).

\subsection{Potentiometric titration}

Potentiometric titration experiments were performed by using a computer controlled titration system (Metrohm $\mathrm{GmbH}$, Filders tadt, Germany) and Tiamo software (Tiamo v2.2, Metrohm GmbH, Filderstadt, Germany). During the titration measurements, the $\mathrm{pH}$ and free $\mathrm{Ca}^{2+}$ concentrations were monitored by utilizing a flat membrane glass electrode (for $\mathrm{pH}$ ) and a polymer based ion selec tive electrode (for $\mathrm{Ca}^{2+}$ selection), respectively. The $\mathrm{CaCl}_{2}(10 \mathrm{mM})$ solution was added at a constant rate of $0.01 \mathrm{~mL} / \mathrm{min}$ to $10 \mathrm{~mL}$ of the protein solution in carbonate buffer $(10 \mathrm{mM})$, which was under constant stirring with a magnetic stir bar at $900 \mathrm{rpm}$. A constant
$\mathrm{pH}$ of 9.75 was maintained by automatic counter titration of $\mathrm{NaOH}$ $(10 \mathrm{mM})$. Calibration and reference experiments were performed by dosing $\mathrm{CaCl}_{2}(10 \mathrm{mM})$ into water ( $\left.\mathrm{pH} 9.75\right)$ and carbonate buffer (10 mM, pH 9.75), respectively. All titration experiments were per formed at room temperature.

\subsection{Fourier transformed infrared spectroscopy (FTIR)}

The titration mixtures were quenched in pure ethanol as de scribed previously (Gebauer et al, 2010). Pellets were collected by centrifugation at $5000 \mathrm{rpm}(3000 \mathrm{~g})$ for $30 \mathrm{~min}$. FTIR analysis of the vacuum dried pellets was done using a Perkin Elmer Spec trum 100 spectrometer (Perkin Elmer Inc., Waltham, MA USA) using an attenuated total reflection (ATR) configuration.

\section{Results and discussion}

\subsection{Bioinformatics analysis}

In order to rationally define the major functional regions of SM50, bioinformatics tools were applied to identify truncated sig nal sequences as well as local regions of the full length protein for protein disorder. The first 17 amino acids were identified to be a secretion signal by using SignalP 4.1 Server (Petersen et al., 2011) to predict the presence and location of signal peptide cleavage sites in a given sequence. The analysis of the SM50 sequence using dis order prediction tools showed lack of structure after the first 100 amino acids of the protein (Fig. 1A), This is in agreement with previous studies where after removal of the repeat region se quences from the full length SM50, the residual sequence dis played about $35 \%$ identity with a family of $\mathrm{C}$ type lectins (Harkey et al., 1995). This C type lectin domain in SM50 also harbors a pro line rich site towards its $C$ terminal.

Within the region predicted to be disordered, the $\mathrm{C}$ terminal contains a Pro and Asn rich region that is 20 residues in length. This short domain contains tandem repeats and adopts an
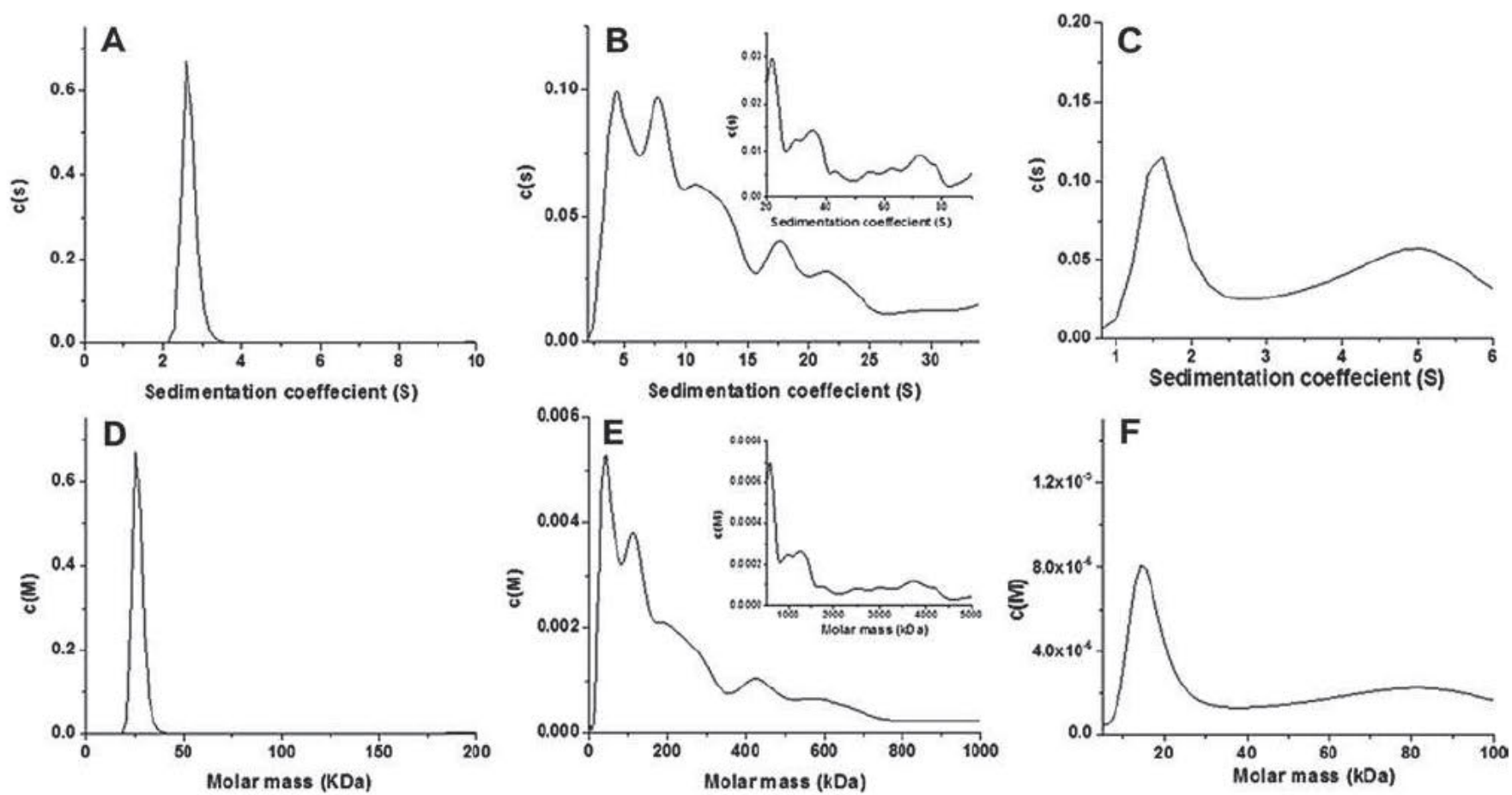

Fig.2. Continuous sedimentation coefficient and molar mass distribution from sedimentation velocity experiments of (A and D) SUMO-CTL(B and E) SUMO-GRR and (C and F) SUMO-PRR, respectively from SEDFIT analysis. 
extended conformation in solution as shown by solution state NMR studies (Zhang et al., 2000). Recent mass spectrometry based analyses of whole organic extracts from sea urchin spicules reported a protein (NCBI Accession XP_786023) which contains a SH3 domain (predicted using SMART, E value 7.34e 15) (Mann et al., 2010). SH3 domains are known for their regulatory activity by binding to proline rich sites (Aitio et al., 2010; Alexandropoulos et al., 1995; Ren et al., 1993). Hence, it is possible that the proline rich region of SM50 is involved in such protein protein interactions during protein transport. The third region of SM50 lie between residues 139 and 410 . It is marked by Gly and Gln rich repeats and its secondary structure is expected to have high $\beta$ turn content (Xu and Evans, 1999). Thus, these three regions of interest were expressed as SUMO fusion proteins include (i) the $\mathrm{C}$ type lec tin (CTL) domain, (ii) Gly rich region (GRR) and (iii) Pro rich region (PRR) as shown in Fig. 1B. Although bioinformatics based glycosyl ation prediction indicates 0 linked glycosylation at residues 122 , 123, 124, 127, 136 and 138 and no N linked glycosylation (SI Fig. 2), previous studies have indicated SM50 to be non glycosyl ated protein at the repeat regions (Killian and Wilt, 1996) (Living ston et al., 2006). Hence, a prokaryotic system was selected for protein expression. The SUMO fusion system was selected due to advantages in expression and purification such as improved protein folding, enhanced expression and having flexible $\mathrm{N}$ and C termini (Butt et al., 2005).

\subsection{Analytical ultracentrifugation}

The sedimentation coefficient and molar mass distributions of the SUMO fusion proteins were obtained by fitting the experimen tal data to the Lamm equation model using SEDFIT (Fig. 2) (assum ing partial specific volumes of $0.718,0.714$ and $0.718 \mathrm{ml} / \mathrm{g}$ for SUMO CTL, SUMO GRR and SUMO PRR, respectively as calculated from the primary amino acid sequence). The sedimentation coefficient distribution for SUMO CTL revealed a major peak at $2.5 \pm 0.4 \mathrm{~S}(27.3 \pm 2.8 \mathrm{kDa})$ (all errors are \pm standard deviations of Gaussian fits to the experimental distributions)(Fig. 2A and B). This corresponds to a pure monomer taking the molar mass of $12.9 \mathrm{kDa}$ for SUMO and $13.6 \mathrm{kDa}$ for the CTL domain in account. The distribu tions for SUMO GRR presented a peak at $3.9 \pm 0.2 \mathrm{~S}(39.0 \pm 4.1 \mathrm{kDa})$ as well as peaks at $7.7 \pm 3.2 \mathrm{~S}, 10.7 \pm 2.7 \mathrm{~S}, 13.4 \pm 2.9 \mathrm{~S}, 17.6 \pm 2.5 \mathrm{~S}$, $21.6 \pm 3.1 \mathrm{~S}, 29.5 \pm 3.2 \mathrm{~S}$ and $35.7 \pm 3.8$. (Errors are given as standard deviations of a Gaussian fit of the distribution). By using Gaussian multiple peak fitting, the relative concentrations were found to be $22.1 \%, 21.3 \%, 11.7 \%, 10.1 \%, 9.9 \%, 6.6 \%, 5.3 \%$ and $4.6 \%$ for the monomer and oligomers, respectively (see inset Fig. 2B and E). Furthermore, the data indicated that the glycine rich protein can oligomerize to form large protein assemblies. These exhibited molar masses of the oligomers were $130 \pm 55 \mathrm{kDa}, 214 \pm 57 \mathrm{kDa}$, $300 \pm 62 \mathrm{kDa}, \quad 460 \pm 57 \mathrm{kDa} ; 601 \pm 107 \mathrm{kDa}, 975 \pm 103 \mathrm{kDa}$ and $1282 \pm 214 \mathrm{kDa}$. The defined molar mass of the assemblies indicates an irreversible interaction because a reversible interaction on a time scale faster than the duration of the ultracentrifuge experiment of a few hours would result in a single peak comprising the time average of the different oligomers. The protein SUMO PRR displayed a $16.8 \pm 3.8 \mathrm{kDa}$ peak at $2.5 \pm 0.0 \mathrm{~S}$ corresponding to the monomer ( $3.9 \mathrm{kDa}$ for the PRR domain $+12.9 \mathrm{kDa}$ for SUMO) and the peak at $5.3 \pm 0.7 \mathrm{~S}(85.1 \pm 14.3 \mathrm{kDa})$ likely indicates the pentamer $(46 \%)$. Self assembly of the proline rich region was possibly due to hydro phobic interactions between the pyrolidine rings and hydrogen bonding interactions between the Asn residues (Zhang et al., 2000). It must be noted that the AUC data confirms the SDS PAGE results for the monomers shown in Fig. 1C.

To determine the protein domain solution structure via the frictional ratio $\left(f / f_{0}\right)$ of these protein species, the sedimentation velocity data was analyzed by the 2 DSA Monte Carlo method
(Ultrascan, Fig. 3 and SI Fig. 3). As SUMO is known to have a well folded, globular structure (Mueller et al., 2001), a $f / f_{o}$ value close to unity can be assumed for the fusion tag. The SUMO CTL fu sion protein displayed a peak at about $27 \mathrm{kDa}$ corresponding to the monomer species. This species had a $f / f_{0}$ value of 1.1 indicating that the CTL domain had a spherical hydrodynamic shape and globular structure with $a=1.94 \mathrm{~nm}$ and $b=1.00 \mathrm{~nm}$ (Fig. 3A). The 2 DSA analysis showed that SUMO GRR and SUMO PRR monomers sedi ment as single species. While SUMO GRR has a globular structure with $f / f_{0}=1.1(a=2.1 \mathrm{~nm}, b=1.9 \mathrm{~nm})$, the SUMO PRR has a high $\mathrm{f} / \mathrm{f}_{o}$ value of 2.8 (Fig. 3B and C). By approximating the hydrody namic shape to a prolate ellipsoid of revolution, the axial ratios $a / b$ for SUMO PRR was calculated. These corresponded to axial dimensions of 21.1 and $0.5 \mathrm{~nm}$ ( $a$ and $b$ values, respectively) for SUMO PRR. This indicated an extended conformation for these monomer species, which is in agreement with previous (Zhang et al., 2000). However, the $f / f_{0}$ of 2.8 for SUMO PRR cannot simply be translated into the dimensions of an extended chain via a pro late ellipsoid of revolution since it extends the length of the stretched molecule ( $10.5 \mathrm{~nm}$ for 35 amino acids).

For SUMO GRR, relatively large oligomers (120, 240 and $840 \mathrm{kDa}$ ) were observed corresponding to $\mathrm{f} / \mathrm{f}_{0}$ values of $1.6,1.7$ and 3.6, respectively. The aggregates at 120 and $240 \mathrm{kDa}$ have a
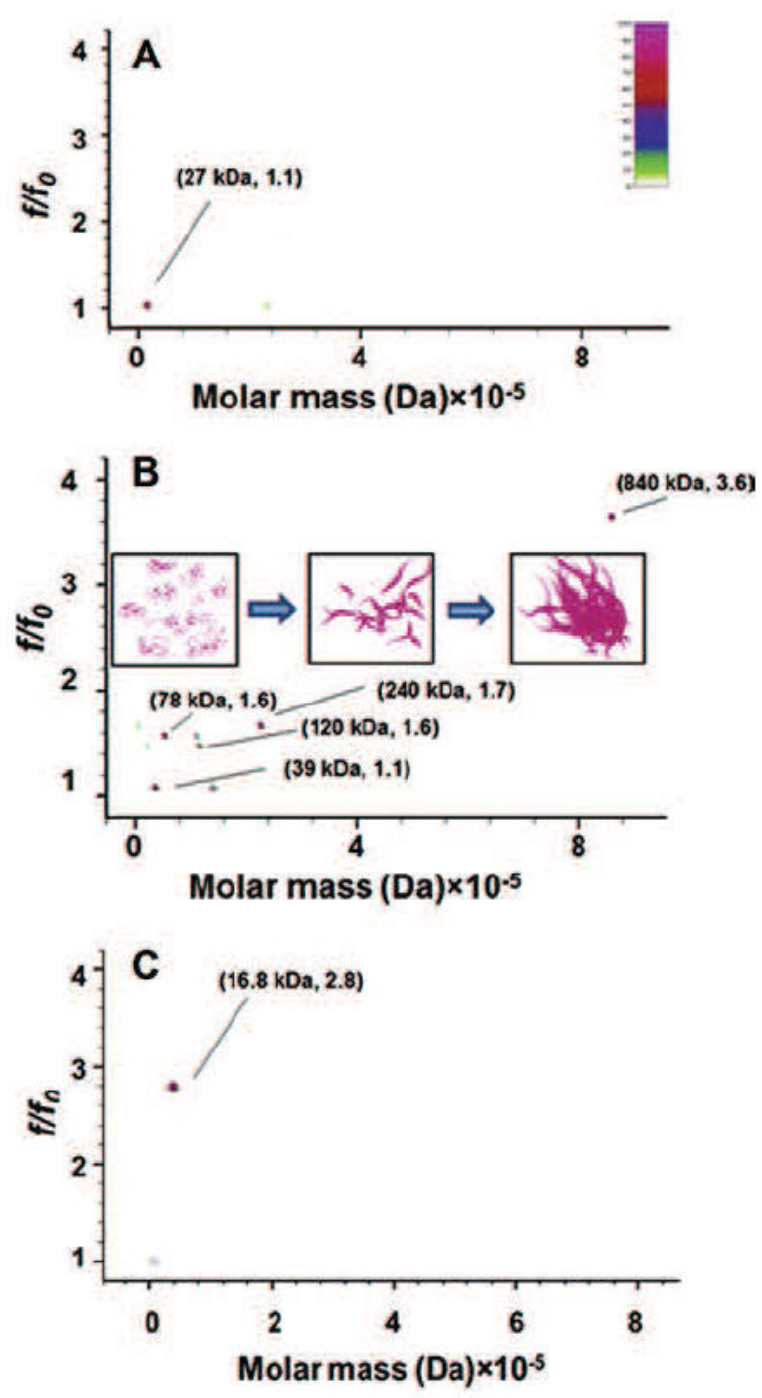

Fig.3. Pseudo 3-dimensional plots for the 2-DSA analysis for (A) SUMO-CTL, (B) SUMO-GRR and (C) SUMO-PRR. Schematic representation of stages in SUMO-GRR assembly is depicted (B, inset). 
rod like shape corresponding to an axial ratio of 12.3 and 15.3 , respectively. Moreover, the prolate ellipsoid axial ratio for the lar ger protein assembly ( $840 \mathrm{kDa})$ was 80.5 . While the smaller oligo mers have an extended shape, larger oligomers become more compact and sheet like. Therefore, self assembly of SUMO GRR ap pears to involve the association of rod like assemblies into sheet like superstructures (Fig. 3B).

DLS of the SUMO fusion proteins was performed to check whether $\mathrm{Ca}^{2+}$ ions induce protein oligomerization. The size distri butions are presented in Fig. 4A. There was no observable aggrega tion for the SUMO protein (SI Fig. 4D), SUMO CTL and SUMO PRR proteins in the presence of $\mathrm{Ca}^{2+}$ ions. However, SUMO GRR formed particles about $27 \pm 8 \mathrm{~nm}$ in average size, which increased propor tionally with $\mathrm{Ca}^{2+}$ ion concentration $(95 \pm 16 \mathrm{~nm}$ in presence of $5 \mathrm{mM} \mathrm{CaCl}{ }_{2}$ ). It must be noted that DLS is not a fractionating technique and thus, an average of all oligomers sizes is detected. Previous studies have reported a similar effect for certain biomin eralization proteins such as amelogenin and Asprich 3 (Bromley et al., 2011; Ndao et al., 2012). The glycine rich region of SM50 is devoid of highly charged, polar residues such as Asp and Glu. Hence, the charge neutralization based protein oligomers pro posed for Asprich 3 (Ndao et al, 2012) may not be true for SUMO GRR. In contrast, the growth of amelogenin oligomers has been attributed to hydrophobic interactions as well as protein dis order (Bromley et al., 2011). Hence, a similar mechanism may exist for the self assembly of the glycine rich region. TEM image of these roughly spherical protein aggregates is depicted in Fig. 5, confirm ing the aggregate size range as determined by DLS. In addition, taking the high frictional ratio of the oligomers without $\mathrm{Ca}^{2+}$ ions into account, TEM micrographs can also be construed as an almost round sheet instead of a sphere. As DLS was performed after filtration of the sample, larger protein aggregates were possibly excluded during these measurements,
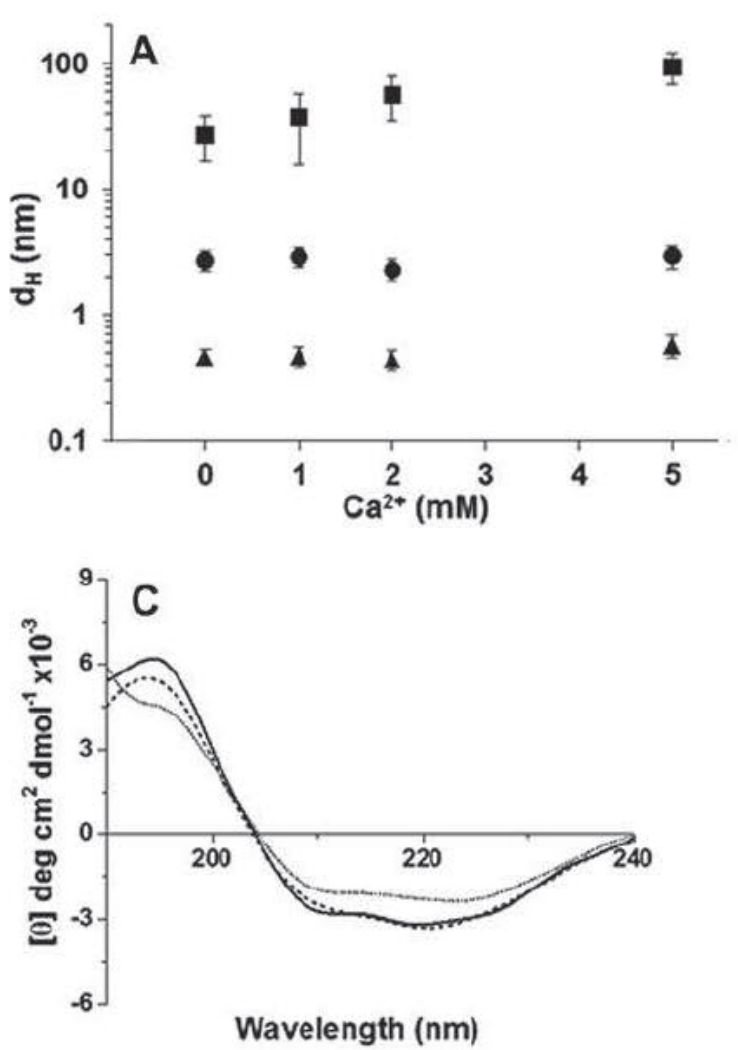

\subsection{Circular dichroism spectroscopy}

Circular dichroism (CD) measurements were performed to investigate the effect of $\mathrm{Ca}^{2+}$ ions on protein secondary structure. The far UV CD spectra of the proteins are shown in Fig. 3. Using K2D3, the secondary structure content percentages were predicted for SUMO CTL, SUMO GRR and SUMO PRR, respectively, with respect to different $\mathrm{Ca}^{2+}$ ion concentrations (Table 2). An increase in $\mathrm{Ca}^{2+}$ concentration led to a decrease in a helix content of SUMO CTL from $33.5 \%$ to $27.4 \%$, while the $\beta$ strand content increased from $19 \%$ to $27.4 \%$. Thus, the $\mathrm{Ca}^{2+}$ ions induced a change in the secondary structure of SUMO CTL marked by an increase in the $\beta$ strand content. For SUMO GRR, the a helix content decreased significantly from $17.19 \%$ to $5.32 \%$ at higher $\mathrm{Ca}^{2+}$ concentration, however the $\beta$ strand content (33.5 $\pm 0.4 \%$ ) did not change signifi cantly. Contrary to a previous study (Xu and Evans, 1999), no bands typical of $\beta$ turns were detected for the glycine rich domain. This can be an effect of the different solvents used in the studies or the presence of a 'hybrid' $C D$ spectrum on account of different sec ondary structures that mask the $\beta$ turn component (Feeney et al. 2003). In the present study, the buffer carbonate anions could have led to intermolecular $\beta$ sheet formation at expense of the $\beta$ turns. This effect has been reported in relation to water content for wheat glutenin, a protein containing Gln rich repeats (Feeney et al., 2003). The protein self assembly and enhanced $\beta$ strand content observed for SUMO GRR are indicative of a similar phenomenon. Livingstone et al. (1991) also predicted a unique $\beta$ spiral supersec ondary structure for pLSM1 from Lytechinus pictus, a homologue of SM50. For SUMO PRR, the presence of $\mathrm{Ca}^{2+}(10 \mathrm{mM})$ in the protein mixture did not affect the CD spectra, although minor changes in intensity were observed. The spectra displayed a negative band at $206 \mathrm{~nm}$ as reported earlier for the CD spectra of a 20 residue peptide domain of the proline rich region (Zhang et al., 2000). This

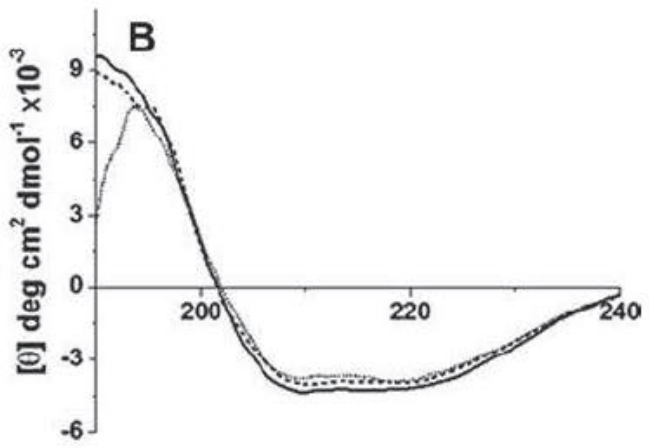

Wavelength $(\mathrm{nm})$

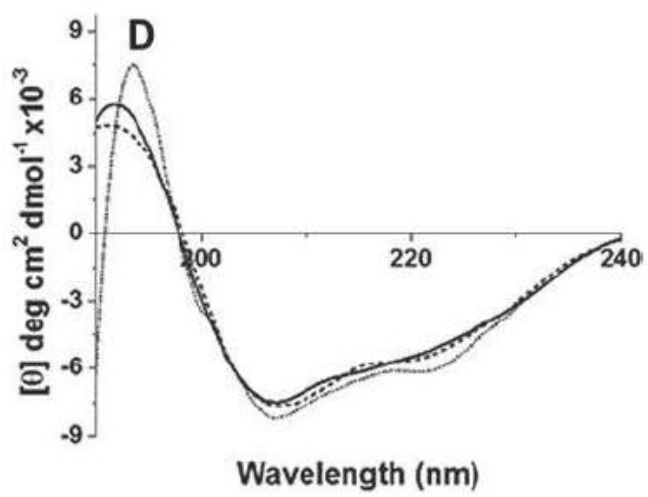

Fig.4. Solution studies of SUMO-CTL, SUMO-GRR, and SUMO-PRR (A) Hydrodynamic radii of proteins at different Ca ${ }^{2+}$ concentrations [SUMO-CTL ( $\bullet$ ), SUMO-GRR ( $\square$ ) and SUMO-PRR ( $\mathbf{\Lambda})$ ]. Representative CD spectra for (B) SUMO-CTL, (C) SUMO-GRR and (D) SUMO-PRR in presence of different Ca ${ }^{2+}$ concentrations [0 mM ( ), $1 \mathrm{mM}$ (--) and $10 \mathrm{mM}(\bullet \bullet \bullet \bullet \bullet \bullet \bullet \bullet)]$. 


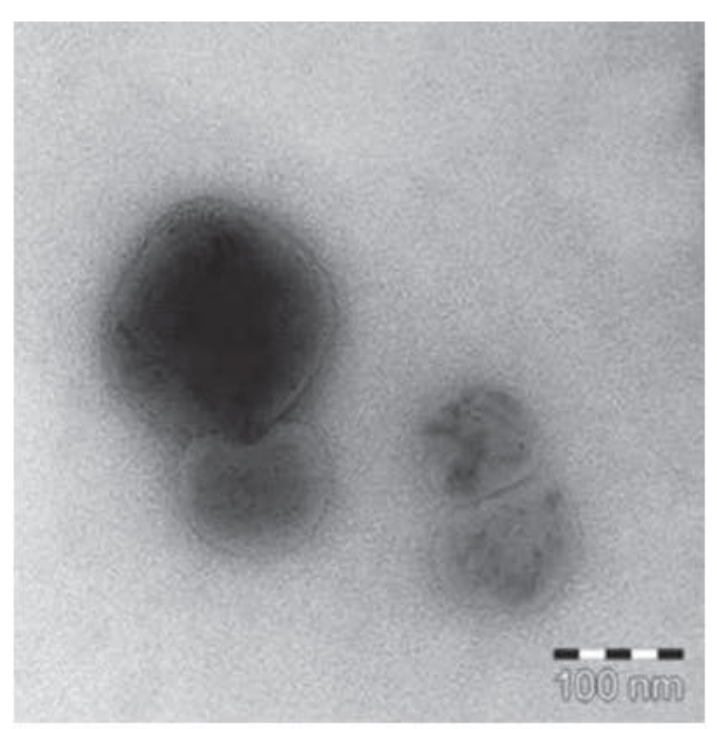

Fig.5. Representative TEM image of particles formed after SUMO-GRR self-assembly in the presence of $\mathrm{Ca}^{2+}$ ions $(5 \mathrm{mM})$.

confirms that the proline rich domain does not adopt a poly L proline type II conformation. During the CD experiments, there was no visible aggregation in the SUMO CTL and SUMO PRR samples, however SUMO GRR samples displayed an aggregate formation in the presence of $\mathrm{Ca}^{2+}$ ions.

From these $\mathrm{CD}$ spectra, we conclude that interactions with $\mathrm{Ca}^{2+}$ ions lead to structural reordering of SUMO CTL and SUMO GRR. For the latter molecule, this can explain the suggested increased hydrophobic interactions leading to the aggregation upon $\mathrm{Ca}^{2+}$ ion addition as observed by DLS on top of the inherent aggregation tendency of this molecule already observed by AUC without the presence of $\mathrm{Ca}^{2+}$ ions. Similar conformational changes induced by $\mathrm{Ca}^{2+}$ ions have been reported earlier with biomineral associated proteins such as dentin matrix proteins (Hao et al., 2007). The ef fect of $\mathrm{Ca}^{2+}$ ions on the $\mathrm{N}$ terminal SUMO tag was also checked (SI Fig. 4E). At $1 \mathrm{mM}$, there was no significant change in the esti mated secondary structure of the SUMO protein, whereas at $10 \mathrm{mM}$, the a helix content decreased by about $5 \%$.

\section{4. $\mathrm{SM} 50$ domain influence on $\mathrm{CaCO}_{3}$ mineralization}

The influence of proteins on the growth of calcium carbonate particles was evaluated by gas/vapor diffusion assays. Fig. 6 shows the different morphologies of calcium carbonate particles formed using (A) 0.01 and (B) $0.1 \mathrm{mg}$ protein each at $1 \mathrm{mM}$ and $100 \mathrm{mM}$ $\mathrm{CaCl}_{2}$ concentrations. At low concentration of SUMO CTL and $1 \mathrm{mM} \mathrm{CaCl} 2$, rhombohedral crystals typical of calcite were observed with few exhibiting a terraced morphology. This mor phology was typical for crystals observed for 0.01 and $0.1 \mathrm{mg}$ of SUMO PRR at $1 \mathrm{mM} \mathrm{CaCl} 2$ as well. An increased concentration of SUMO CTL led to formation of crystals with rounded edges as well as irregular, dumbbell like particles (Fig. 6B(i)). The theoretical pI

Table 2

Secondary structure content of SUMO fusion proteins estimated using K2D3 analysis.

\begin{tabular}{|c|c|c|c|c|c|c|}
\hline \multirow[t]{2}{*}{$\mathrm{Ca}^{2+}(\mathrm{mM})$} & \multicolumn{2}{|c|}{ SUMO-CTL } & \multicolumn{2}{|c|}{ SUMO-GRR } & \multicolumn{2}{|c|}{ SUMO-PRR } \\
\hline & a helix & $\beta$ strand & a helix & $\beta$ strand & a helix & $\beta$ strand \\
\hline 0 & 33.54 & 19 & 17.19 & 33.54 & 38.35 & 4.71 \\
\hline 1 & 28.89 & 21.43 & 14.91 & 33.83 & 37.41 & 4.79 \\
\hline 10 & 25.83 & 27.48 & 5.32 & 33.11 & 35.34 & 5.46 \\
\hline
\end{tabular}

of SUMO CTL, SUMO GRR and SUMO PRR are pH 5.37, 10.48, and 6.05 , respectively. The absolute charge of these molecules at $\mathrm{pH}$ 9.75 is 19.1 for SUMO CTL, +6.7 for SUMO GRR and 7.2 for SUMO PRR. SUMO CTL has a relatively higher negative charge at the $\mathrm{pH}$ conditions during the mineralization experiment $(\mathrm{pH}$ 9.75). This indicates that electrostatic interactions between SUMO CTL residues and the crystal surface should be weak. How ever, a previous report also described the formation of calcite with distinct morphologies using positively charged polymers (Cantaert et al., 2012) like the GRR under the applied pH conditions.

With $1 \mathrm{mM} \mathrm{CaCl}_{2}$, at low concentrations of SUMO GRR, regular rhombohedral calcite crystals were observed. A higher amount of SUMO GRR led to truncated growth of large crystals as well as dis playing step like features. Similar crystal morphology has been re ported for calcite grown in the presence of polymers and small molecules such as poly Asp and lysozyme (Politi et al., 2007; Wang et al., 2009). On a few crystal surfaces, pores were also seen (Fig. 6A(iii) and $\mathrm{B}(\mathrm{iii})$ ). Such features have been reported earlier for calcite crystals grown in the presence of Asprich Fragment 1 proteins and were attributed to irregular crystal growth rates (De lak et al., 2008). At $100 \mathrm{mM} \mathrm{CaCl}_{2}$, spheriod like and dumb bell shaped calcium carbonate particles were observed in the presence of both low and high concentrations of SUMO CTL. Few spindle shaped particles were also observed (Fig. 6A(ii)). These can be ex plained as an intermediate stage in growth of the dumbbell shaped particles (Kniep and Busch, 1996; Xiang et al., 2008).

The SUMO GRR protein has a high theoretical isoelectric point (pI 10.48) and hence, was expected to affect crystal growth on ac count of its positive charge. The protein mediated the formation of crystals with rounded edges and spherulitic particles at 0.01 and $0.1 \mathrm{mg}$ protein content, respectively, both at $100 \mathrm{mM} \mathrm{CaCl}_{2}$ con centration. Some spherulites displayed a polycrystalline surface (Fig. 6B(iv)) and are similar to those reported for calcium carbonate precipitated in the presence of egg shell associated and mollusk shell prismatic associated proteins (Ajikumar et al., 2003; Delak et al., 2008; Kim et al., 2004; Pokroy et al., 2007). These results indicate that this protein affects crystal morphology by influencing the early stages of nucleation or directly influencing a growing crystal surface.

With $0.01 \mathrm{mg}$ of SUMO PRR, the calcium carbonate particles displayed splayed surfaces (arrow, Fig. 6A(vi)). This can possibly be due to the protein molecules binding to certain sites on the crystal surface, thereby affecting the kinetics of crystal growth. This effect was more pronounced at higher protein concentration (Fig. 6B(vi)). In addition, these particles also exhibited an irregular dumbbell like shape. Hence, it was seen that all proteins contain ing domains of SM50 affected the morphology of calcium carbon ate particles, especially at higher protein concentrations. The morphologies at high $\mathrm{CaCO}_{3}$ and protein concentrations are typical morphologies which are expected for diffusion limited spherulitic growth at a high driving force for crystallization (Oaki and Imai, 2003). For these protein additives, aggregates were also observed, although there were no distinct interactions with the mineral par ticles (SI Fig. 5). The control experiments in the absence of proteins showed rhombohedral crystals and few spherulites (arrow, SI Fig. 4A). In presence of the SUMO protein, the crystals displayed a terraced morphology (SI Fig. 4B and C).

\subsection{Potentiometric titration}

To confirm whether a few of the SM50 SUMO fusion proteins maintain effects at early stages of mineralization, a technique to investigate processes before nucleation would provide insight into these early mineralization processes. We studied the effect of these proteins on early stages of calcium carbonate mineralization prior to nucleation processes through the use of potentiometric titration 


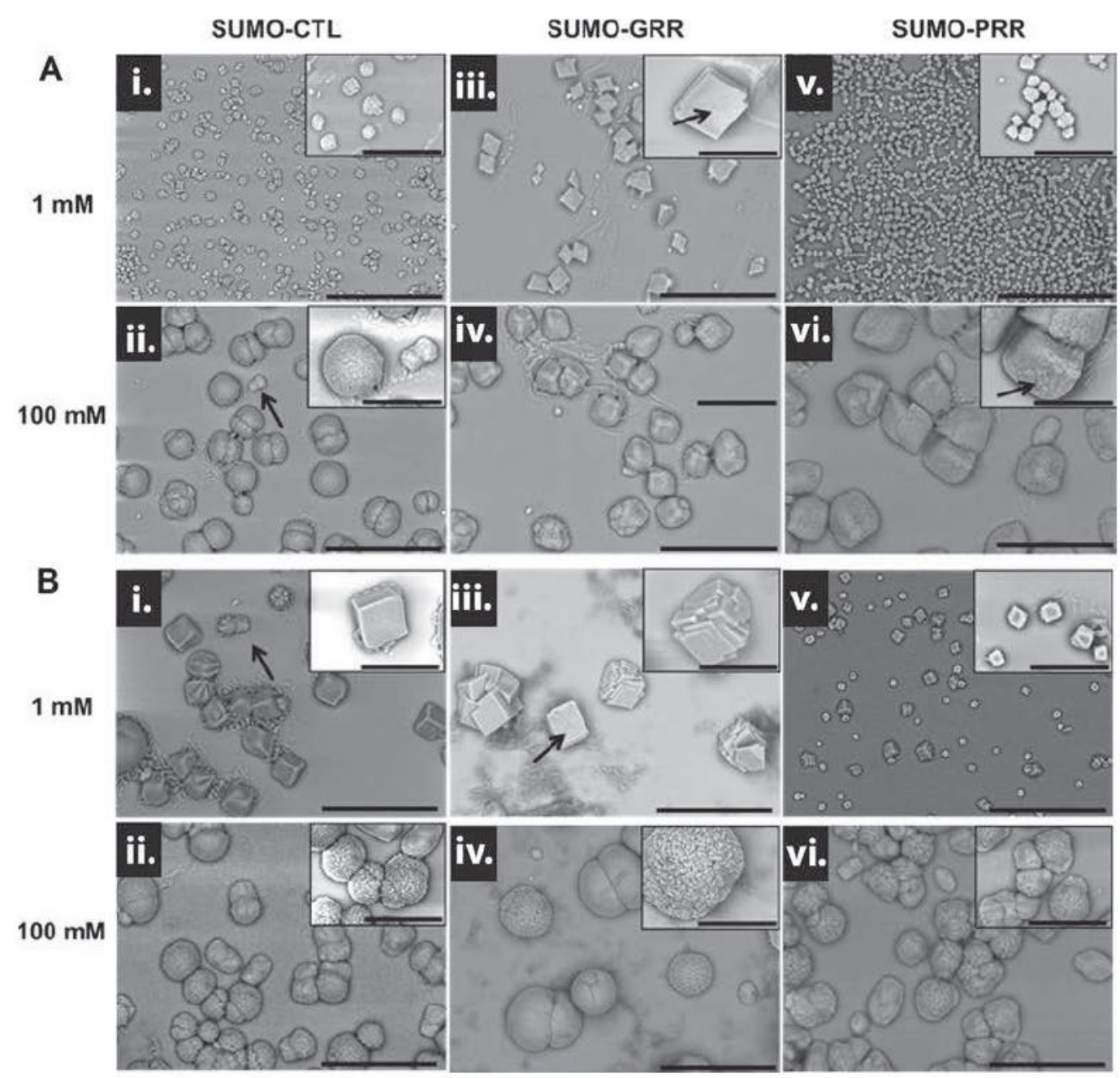

Fig.6. Representative SEM images of calcium carbonate particles from gas diffusion assays using $1 \mathrm{mM}$ and $100 \mathrm{mM} \mathrm{CaCl} 2$ in the presence of (A) $0.01 \mathrm{mg}$ and (B) $0.1 \mathrm{mg}$ protein, respectively. Bars indicate $50 \mu \mathrm{m}$ (1200×, panel figures) and $20 \mu \mathrm{m}$ (5000×, inset figures).

assays at constant $\mathrm{pH}$. The slope of the initial increase in free $\mathrm{Ca}^{2+}$ ions prior to nucleation, the time of nucleation and the solubility of the nucleated precipitate were considered since it is known from prior studies that these may be significantly altered by soluble additives (Gebauer and Coelfen, 2011; Gebauer et al., 2010; Gebauer et al., 2008; Verch et al., 2011). The plots of free $\mathrm{Ca}^{2+}$ ion concentrations with respect to time are presented in Fig. 7(A C). At $0.1 \mathrm{mg} / \mathrm{mL}$ protein concentrations, the pre nucle ation slope was not affected significantly. However, at higher con centrations, SUMO CTL displayed a minor increase in the slope, indicating a destabilizing effect on prenucleation clusters (Fig. 7A.) (Gebauer and Coelfen, 2011; Gebauer et al., 2008). This can be related to the characteristic $\mathrm{Ca}^{2+}$ ion binding properties of C type lectins (Drickamer and Dodd, 1999). On the other hand, SUMO GRR and SUMO PRR did not exhibit a significant change in the pre nucleation slope at $1 \mathrm{mg} / \mathrm{mL}$ (Fig. 7B and C).

A direct relation between the time of nucleation with the protein concentration for all proteins was observed. This effect is described by defining a normalized nucleation time, $\tau_{n u c}$ as the quotient of the nucleation time in the presence of protein and that of the carbonate buffer reference (Picker et al., 2012). At $0.1 \mathrm{mg} /$ $\mathrm{mL}$, there was no significant difference among the time points of nucleation for SUMO CTL, SUMO GRR and SUMO PRR. However, at $1 \mathrm{mg} / \mathrm{mL}$, the $\tau_{\text {muc }}$ values were $2.55,3.80$ and 2.17 for SUMO CTL, SUMO GRR and SUMO PRR, respectively. This indicated that the glycine rich repeat region of SM50 was comparatively more effective in stabilizing the prenucleation clusters of calcium carbonate, which delays their coalescence and nucleation of the resulting phase. The most abundant amino acids in this repeat region are glycine, glutamine, proline, arginine and asparagine. According to a previous report (Picker et al., 2012), Arg and Pro do not alter the nucleation time, whereas the other amino acids such as Asn $\left(\tau_{n u c}=1.26\right)$, Gly $\left(\tau_{n u c}=1.2\right)$, and $\operatorname{Gln}\left(\tau_{n u c}=1.19\right)$ delay nucleation (at $10 \mathrm{mM} \mathrm{CaCl}_{2}$ concentration). It can be concluded that in addition to amino acid composition, other factors governed by protein conformation such as solvent exposed amino acid resi dues and surface charge distribution are likely to play an important role in the stabilization of prenucleation clusters. An intriguing observation is that the glycine rich and proline rich regions are abundant in Asn residues each containing 15 and 13 Asn residues, respectively. Nevertheless, SUMO PRR was not as effective as SUMO GRR in stabilizing prenucleation clusters, emphasizing the role of protein structure in prenucleation cluster stabilization.

The measured solubility products of the nucleated phases are indicative of various amorphous or crystalline calcium carbonate polymorphs formed after nucleation (Fig. 7D F). It should be noted that in these experiments, the measured solubility is indicative of the most soluble phase present and therefore, phases with lower solubilities present in lower amounts are not identified. The refer ence with carbonate buffer ( $\mathrm{pH} 9.75$ ) yielded a solubility product $\left(\mathrm{Ksp} \approx 3.7 \times 10^{8} \mathrm{M}^{2}\right.$ ) that was indicative of proto vaterite ACC. This was consistent with solubility reported by Gebauer and 
SUMO-CTL
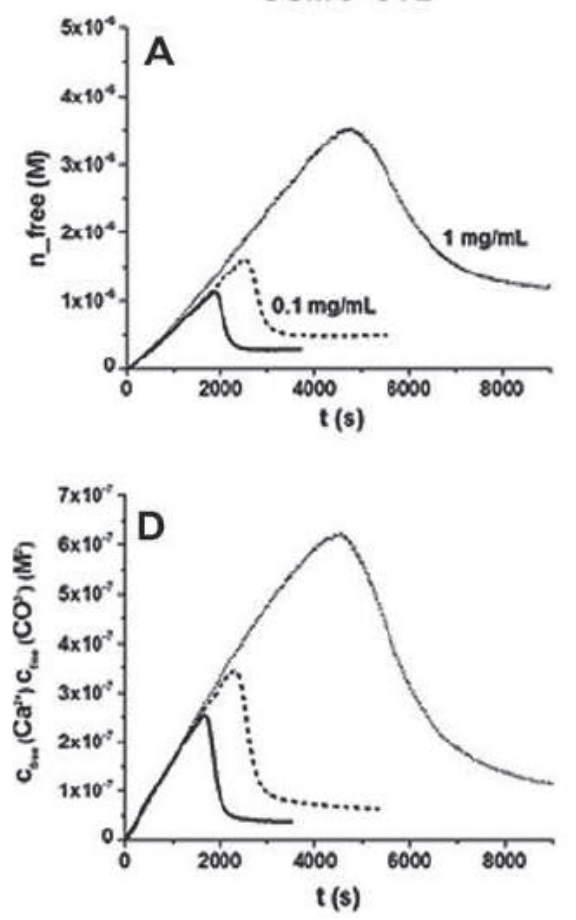

SUMO-GRR
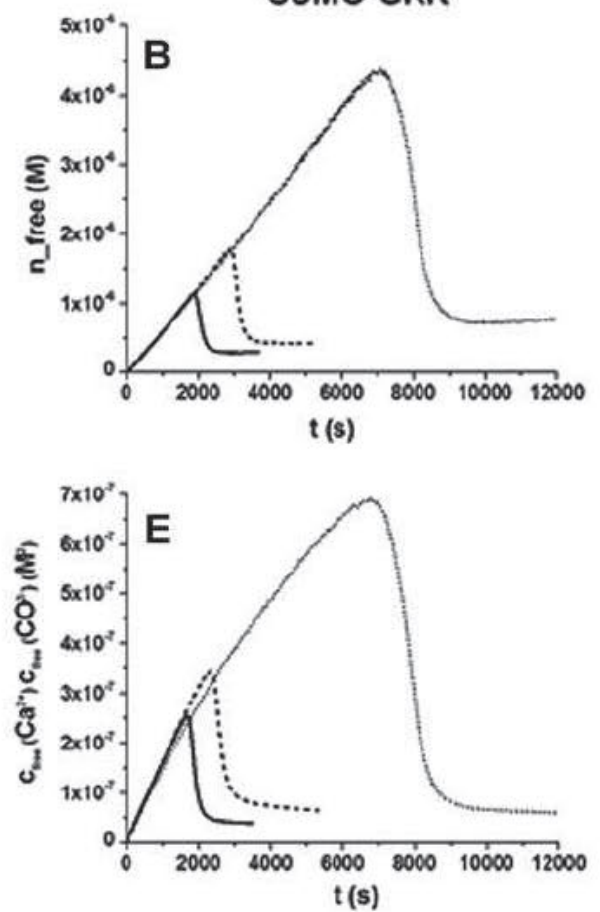

SUMO-PRR
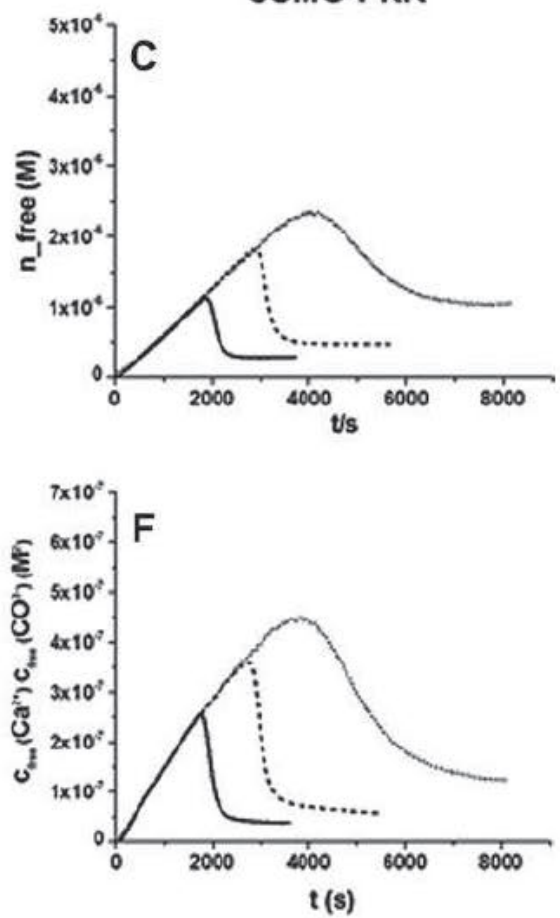

Fig.7. Potentiometric titration assays in the presence of SUMO-CTL, SUMO-GRR, SUMO-PRR (10 mM Carbonate Buffer, pH 9.75) using (A and D) SUMO-CTL, (B and E) SUMO-

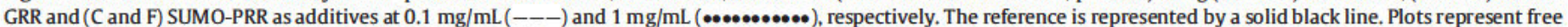
$\mathrm{Ca}^{2+}$ concentration $(\mathrm{A}-\mathrm{C})$ or solubility product $(\mathrm{D}-\mathrm{F})$ with respect to time.

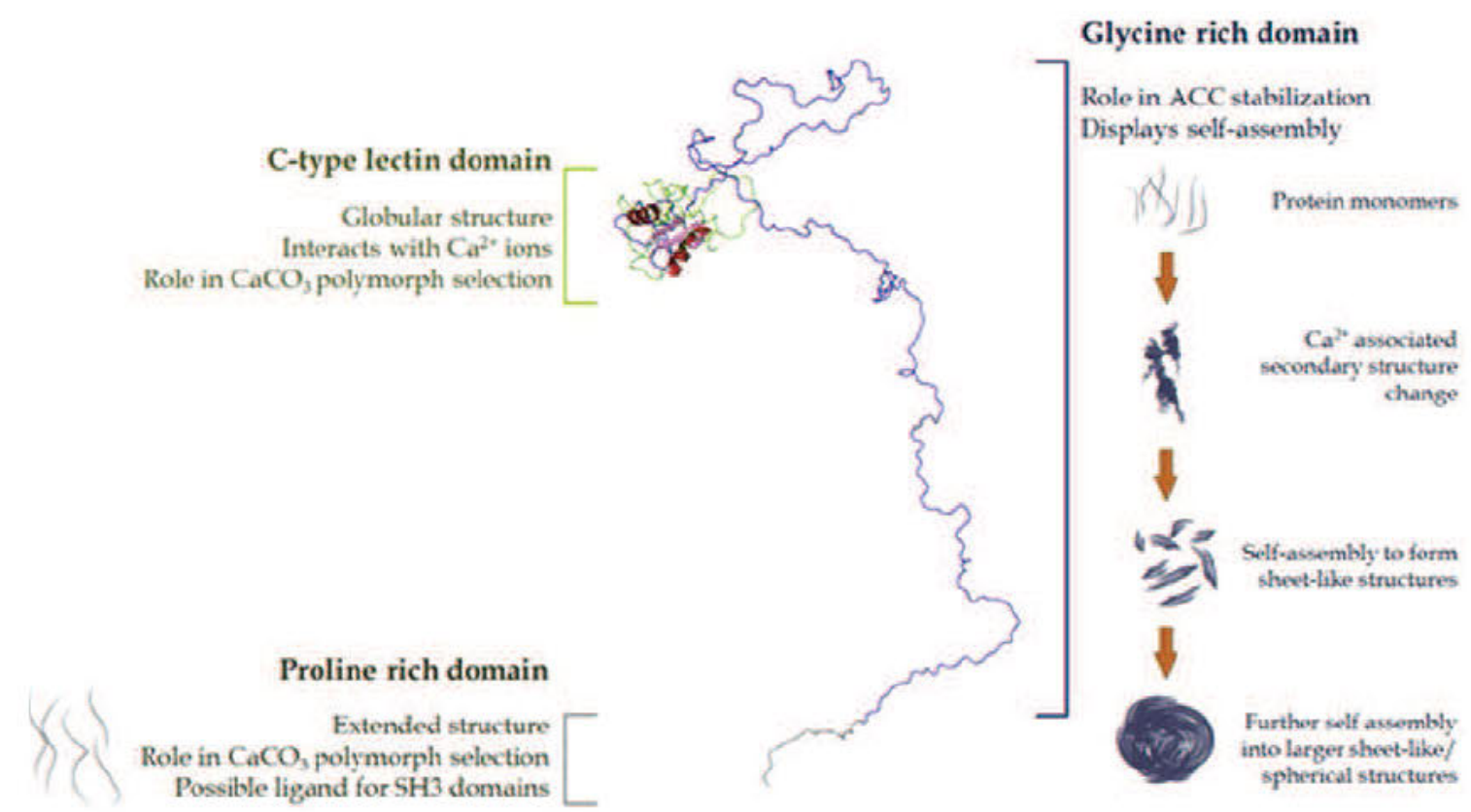

Fig.8. Schematic representation of SM50 domains and their putative functions A model of SM50 was predicted using DISOCLUST/nFOLD3 server (Jones et al, 2005; McGuffin, 2008). Although the quality-score $(0.0728)$ was low, certain structural features are in agreement with the AUC results such as a globular CTL domain and the extended conformations of the GRR and PRR domains. A scheme has been proposed for the self-assembly of the GRR domain (right) that involves (i) secondary structure changes of monomers induced by $\mathrm{Ca}^{2+}$ ions and (ii) organization into spherical/sheet-like assemblies as observed in AUC and CD solution analyses.

coworkers (Gebauer et al., 2008). In the presence of the SUMO fusion CTL and PRR $(0.1 \mathrm{mg} / \mathrm{mL})$, the solubility products after nucleation were considerably higher than for the reference, specif ically $\mathrm{Ksp}_{\text {(SUMO-CTL) }} \approx 6.43 * 10^{8} \mathrm{M}^{2}, \mathrm{Ksp}_{\text {(SUMO-GRR) }} \approx 6.48 * 10^{8} \mathrm{M}^{2}$ and $\mathrm{Ksp}_{\text {(SUMO-PRR })} \approx 5.73 * 10^{8} \mathrm{M}^{2}$. At increased protein concentrations ( $1 \mathrm{mg} / \mathrm{mL}$ ), the solubility increased up to four times that of the reference (Ksp $\left(\right.$ SUMO-CTL) $\approx 11.60 * 10^{8} \mathrm{M}^{2}$; $\mathrm{Ksp}_{\text {(SUMO-GRR) }} \approx 5.96 * 10^{8} \mathrm{M}^{2}$ and $\mathrm{Ksp}_{\text {(SUMO-PRR) }} \approx 12.50 * 10^{8} \mathrm{M}^{2}$ ). Even higher solubilities have been reported in the literature for a polymer induced liquid precursor (PILP) phase in the case of 
additives such as sodium triphosphate $\left(\mathrm{Ksp} \approx 40 * 10^{8} \mathrm{M}^{2}\right.$ at $0.1 \mathrm{mg} / \mathrm{mL}$ ) and poly (aspartic acid) (Ksp $\approx 20 * 10^{8} \mathrm{M}^{2}$ at $0.1 \mathrm{mg} / \mathrm{mL}$ ) for (Verch et al., 2011). This indicates that proteins SUMO CTL and SUMO PRR also modulate the formation of a PILP like phase (Gower, 2008) or a dense liquid phase (Bewernitz et al., 2012) after the nucleation event. The solubility products for SUMO GRR were about twice that of the reference in the pres ence of protein concentrations at 0.1 and $1 \mathrm{mg} / \mathrm{mL}$. However, in contrast to SUMO CTL and SUMO PRR, the solubilities of SUMO GRR did not increase with respect to the protein content.

\subsection{ATR FTIR}

ATR FTIR analyses of the final titration products were per formed in order to identify nucleated calcium carbonate phases (SI Fig. 6). For SUMO CTL and SUMO PRR, only crystalline polymorphs vaterite and calcite were detected, with a lack of bands unique to the amorphous precursors. Specifically, the crystalline polymorphs vaterite and calcite were detected at 0.1 and $1 \mathrm{mg} / \mathrm{mL}$, respectively for both SUMO CTL and SUMO PRR (SI Fig. $6 \mathrm{~A}$ and $\mathrm{C}$ ). As vaterite is the preferential phase at $\mathrm{pH} 9.75$, the preference for calcite for both proteins at higher concentration suggests an influence on polymorph selection. Alternatively, in the presence of SUMO GRR (SI Fig. 6B), ACC was formed after nucle ation, as indicated by a peak at $1066 \mathrm{~cm}^{1}$ (Anderson and Brečević, 1991). A shoulder peak at $1074 \mathrm{~cm}^{1}$ was also observed, which can be attributed to proto calcite ACC (Gebauer et al., 2010). Our re sults indicate that the glycine rich repeat domain mediates ACC stabilization as well as directs the formation of the proto calcite polymorph.

In order to accurately consider the effect of the SUMO fusion tag on the titration results, experiments were performed using the purified $6(\mathrm{X})$ SUMO tag as an additive at $0.1 \mathrm{mg} / \mathrm{mL}$ (SI Fig. 7). The plot of free $\mathrm{Ca}^{2+}$ ions versus time displayed a minor decrease in slope in the pre nucleation regime. The time required for nucleation $\left(\tau_{n u c}=1.2\right)$ was slightly lower than those observed in the reference experiments and the solubility product after nucleation product did not change significantly (1.06 times the ref erence solubility). Although, the slight increase in solubility could be on account of a glutamate residue that constitute the SUMO protein (Smt3p, NCBI accession NP_010798), the increase is within statistical variation of the reference solubilities. Thus, the SUMO expression system appears ideal for the expression of biomineral ization proteins especially for titration studies.

\section{Conclusion}

The present study demonstrates the distinct roles of major SM50 domains in terms of self assembly, protein secondary structure conformation and calcium carbonate mineralization. The globular SUMO CTL domain investgated here does not display self assembly, but does influence mineralization as demonstrated by gas diffusion and titration studies. Several proteins from the spicule matrix family contain CTL domains in their sequences, hinting at the possibility that this domain may be required for bio mineralization processes. The SUMO glycine rich repeat domain of SM50 displayed aggregation and formed large protein superstruc tures. It is likely that during sea urchin spiculogenesis, such protein self assembly drives ACC stabilization and mineral organization in a manner analogous to amelogenin and calcium phosphate interac tions (Fang et al., 2011). Whereas, the SUMO fusion proline rich repeat domain leads to the formation of calcium carbonate parti cles with distinct morphologies as well as affected the early stages of mineralization. Although this protein showed some aggregation behaviors, no change in secondary structure in response to an increase presence of $\mathrm{Ca}^{2+}$ ions was observed. A scheme summariz ing the diverse behavior of these domains in mineralization processes in relation to the full length SM50 protein is shown (Fig. 8). By examining these major constituents of SM50, we provide clues on the function of the full length SM50 protein as well as the assembly mechanism of SM50 with calcium carbonate mineral phases into the larval sea urchin spicule.

\section{Acknowledgments}

J.K.B. acknowledges the Young Scholar Fund (University of Konstanz) for generous funding of a postdoctoral fellowship. The authors would like to thank Dr. R. Andrew Cameron (Center for Regulatory Genomics, Beckman Institute, Caltech) for support and discussions related to the cloning of SM50. The authors acknowledge Prof. Elke Deuerling (Molecular Microbiology, University of Konstanz) for the plasmid used in the expression of SUMO fusion proteins. We also thank Prof. Wolfram Welte (Structural Biology, University of Konstanz) for useful discussions on the manuscript.

\section{References}

Aitio, O., Hellman, M., Kazlauskas, A., Vingadassalom, D.F., Leong, J.M., et al., 2010 Recognition of tandem PxxP motifs as a unique Src homology 3-binding mode triggers pathogen-driven actin assembly. PNAS 107, 21743-21748.

Ajikumar, P.K., Lakshminarayanan, R., Ong B.T., Valiyaveettil, S., Kini, R.M., 2003. Eggshell matrix protein mimics: designer peptides to induce the nucleation of calcite crystal aggregates in solution. Biomacromolecules 4, 1321-1326.

Alexandropoulos, K., Cheng, G., Baltimore, D., 1995. Proline-rich sequences that bind to Src homology 3 domains with individual specificities. Proc. Natl. Acad. Sci. U.S.A. 92, 3110-3114.

Amos, F.F., Ponce, C.B., Evans, J.S., 2011. Formation of framework nacre polypeptide supramolecular assemblies that nucleate polymorphs. Biomacromolecules 12 , 1883-1890.

Anderson, F.A., Brečević, L., 1991. Infrared spectra of amorphous amd crystalline calcium carbonate. Acta Chem. Scand. 45, 1018-1024.

Belcher, A.M., Wu, X.H., Christensen, R.J., Hansma, P.K., Stucky, G.D., et al., 1996. Control of crystal phase switching and orientation by soluble proteins. Nature 381, 56-58.

Beniash, E., Aizenberg, J., Addadi, L., Weiner, S., 1997. Amorphous calcium carbonate transforms into calcite during sea urchin larval spicule growth. Proc. Roy. Soc. B 264, 461-465.

Bewernitz, M.A., Gebauer, D., Long, J., Coelfen, H., Gower, L.B., 2012. A metastable liquid precursor phase of calcium carbonate and its interactions with polyaspartate. Faraday Discus. 159, 291-312.

Bromley, K.M., Kiss, A.S., Lokappa, S.B., Lakshminarayanan, R., Fan, D., MoradianOldak, J., et al., 2011. Dissecting amelogenin protein nanospheres: characterization of metastable oligomers. J. Biol. Chem. 286, 34643-34653.

Brookes, E., Cao, W., Demeler, B., 2010. A two-dimensional spectrum analysis for sedimentation velocity experiments of mixtures with heterogeneity in molecular weight and shape. Eur. Biophys. J. Biophys. Lett. 39, 405-414.

Cantaert, B., Kim, Y., Ludwig, H., Nudelman, F., Sommerdijk, N.A.J.M., et al., 2012. Think positive: phase separation enables a positively charged additive to induce dramatic changes in calcium carbonate morphology. Adv. Funct. Mater. 22, 907-915.

Delak, K., Giocondi, J., Orme, C., Evans, J.S., 2008. Modulation of crystal growth by the terminal sequences of the prismatic-associated asprich protein. Cryst. Growth Des. 8, 4481-4486.

Diao, J., Tajkhorshid, E., 2008. Indirect Role of Ca2+ in the Assembly of Extracellular Matrix Proteins. Biophys. J. 95, 120-127.

Dosztányi, Z., Csizmók, V., Tompa, P., Simon, I., 2005. IUPred: web server for the prediction of intrinsically unstructured regions of proteins based on estimated energy content. Bioinformatics 21, 3433-3434.

Drickamer, K., Dodd, R.B., 1999. C-type lectin-like domains in Caenorhabditis elegans: predictions from the complete genome sequence. Glycobiology 9, 1357-1369.

Evans, J.S., 2012. Aragonite-associated biomineralization proteins are disordered and contain interactive motifs. Bioinformatics 28, 3182-3185.

Falini, G., Albeck, S., Weiner, S., Addadi, L., 1996. Control of aragonite or calcite polymorphism by mollusk shell macromolecules. Science 271, 67-69. 
Fang, P., Conway, J.F., Margolis, H.C., Simmerd, J.P., Beniash, E., 2011. Hierarchical self-assembly of amelogenin and the regulation of biomineralization at the nanoscale. Proc. Natl. Acad. Sci. U.S.A. 108, 14097-14102.

Feeney, K.A., Wellner, N., Gilbert, S.M., Halford, N.G., Tatham, A.S., et al., 2003. Molecular structures and interactions of repetitive peptides based on wheat glutenin subunits depend on chain length. Biopolymers 72, 123-131.

Foo, C.W.P., Huang, J., Kaplan, D.L., 2004. Lessons from seashells: silica mineralization via protein templating. Trends Biotechnol. 22, 577-585.

Fratzl, P., Weinkamer, R., 2007. Nature's hierarchical materials. Prog. Mater. Sci. 52, 1263-1334.

Fuerst, C.M., Moergelin, M., Vadstrup, K., Heinegard, D., Aspberg, A., et al., 2013. The C-Type lectin of the aggrecan G3 domain activates complement. PLoS One 8,111.

Gasteiger, E., Hoogland, C., Gattiker, A., Duvaud, S., Wilkins, M.R., et al., 2005. Protein Identification and Analysis Tools on the ExPASy Server. Humana Press.

Gebauer, D., Coelfen, H., 2011. Prenucleation clusters and non-classical nucleation. Nano Today 6, 564-584.

Gebauer, D., Gunawidjaja, P.N., Ko, P.J.Y., Bacsik, Z., Aziz, B., et al., 2010. Proto-calcite and Proto-vaterite in amorphous calcium carbonates. Angew. Chem. Int. Ed. 49, 8889-8891.

Gebauer, D., Völkel, A., Cölfen, H., 2008. Stable prenucleation calcium carbonate clusters. Science 322, 1819-1822.

Golovanov, A.P., Hautbergue, G.M., Wilson, S.A., Lian, L., 2004. A simple method for improving protein solubility and long-term stability. J. Am. Chem. Soc. 126, 8933-8939.

Gong, Y.U.T., Killian, C.E., Olson, I.C., Appathurai, N.P., Amasino, A.L., et al., 2012. Phase transitions in biogenic amorphous calcium carbonate. Proc. Natl. Acad. Sci. U.S.A. 109, 6088-6093.

Gower, L.B., 2008. Biomimetic model systems for investigating the amorphous precursor pathway and its role in biomineralization. Chem. Rev. 108, 45514627.

Greenfield, N., 2006. Using circular dichroism to estimate protein secondary structure. Nat. Protoc. 1, 2876-2890.

Gross, P.S., Al-Sharif, W.Z., Clow, L.A., Smith, L.C., 1999. Echinoderm immunity and the evolution of the complement system. Dev. Comp. Immunol. 23, 429-442.

Gur, D., Politi, Y., Sivan, B., Fratzl, P., Weiner, S., et al., 2013. Guanine-based photonic crystals in fish scales form from an amorphous precursor. Angew. Chem. Int. Ed. $52,388-391$.

Hao, J., Narayanan, K., Muni, T., Ramachandran, A., George, A., 2007. Dentin matrix protein 4 a novel secretory calcium-binding protein that modulates odontoblast differentiation. J. Biol. Chem. 282, 15357-15365.

Harkey, M.A., Klueg, K., Sheppard, P., Rudolf, A.R., 1995. Structure, expression and extracellular targeting of PM27, a skeletal protein associated specifically with growth of the sea urchin larval spicule. Dev. Biol 168, 549-566.

Jones, D.T., Bryson, K., Coleman, A., McGuffin, L.J., Sadowski, M.I., et al., 2005. Prediction of novel and analogous folds using fragment assembly and fold recognition. Proteins: Struct. Funct. Bioinf. 61, 143-151.

Kalmar, L., Homola, D., Varga, G., Tompa, P., 2012. Structural disorder in proteins brings order to crystal growth in biomineralization. Bone 51, 528-534.

Katoh-Fukui, Y., Noce, T., Ueda, T., Fujiwara, Y., Hashimoto, N., et al., 1991. The corrected structure of the SM50 spicule matrix protein of Strongylocentrotus purpuratus. Dev. Biol. 145, 201-202.

Kim, I.W., DiMasi, E., Evans, J.S., 2004. Identification of mineral modulation sequences within the nacre-associated oyster shell protein. Cryst. Growth Des, 4, 1113-1118.

Kniep, R., Busch, S., 1996. Biomimetic growth and self-assembly of fluorapatite aggregates by diffusion into denatured collagen matrices. Angew. Chem. Int. Ed. 108, 2623-2626.

Livingston, B., Killian, C.E., Wilt, F.H., 2006. A genome wide analysis of biomineralization-related proteins in the sea urchin Strongylocentrotus purpuratus. Dev. Biol. 300, 335-348

Louis-Jeune, C., Andrade-Navarro, M.A., Perez-Iratxeta, C., 2012. Prediction of protein secondary structure from circular dichroism using theoretically derived spectra. Proteins $80,374-381$

Mann, K., Wilt, F.H., Poustka, A.J., 2010. Proteomic analysis of sea urchin (Strongylocentrotus purpuratus) spicule matrix. Proteome Sci. 8, 33.

McGuffin, L.J., 2008. Intrinsic disorder prediction from the analysis of multiple protein fold recognition models. Bioinformatics 24, 586-587.

Metzler, R.A., Evans, J.S., Killian, C.E., Zhou, D., Churchill, T.H., et al., 2010. Nacre protein fragment templates lamellar aragonite growth. J. Am. Chem. Soc. 132, 6329-6334.

Mueller, S., Hoege, C., Pyrowolakis, G., Jentsch, S., 2001. SUMO, ubiquitin's mysterious cousin. Nat. Rev. Mol. Cell Biol. 2, 202-210.

Ndao, M., Keene, E., Amos, F.F., Rewari, G., Ponce, C.B., et al., 2010. Intrinsically disordered mollusk shell prismatic protein that modulates calcium carbonate crystal growth. Biomacromolecules 11, 2539-2544.
Ndao, M., Ponce, C.B., Evans, J.S., 2012. Oligomer formation, metalation, and the existence of aggregation-prone and mobile sequences within the intracrystalline protein family, asprich. Faraday Discuss. 159, 449-462.

Nonoyama, T., Ogasawara, H., Tanaka, M., Higuchi, M., Kinoshita, T., 2012. Calcium phosphate biomineralization in peptide hydrogels for injectable bone-filling materials. Soft Matter 8, 11531-11536.

Oaki, Y., Imai, H., 2003. Experimental demonstration for the morphological evolution of crystals grown in gel media. Cryst. Growth Des. 3, 711-716.

Petersen, T.N., Brunak, S., von Heijne, G., Nielsen, H., 2011. SignalP 4.0: discriminating signal peptides from transmembrane region. Nat. Methods 8 , 785-786.

Picker, A., Kellermeier, M., Seto, J., Gebauer, D., Cölfen, H., 2012. The multiple effects of amino acids on the early stages of calcium carbonate crystallization. Z. Kristallogr./Crystalline mat. 227, 744-757.

Pokroy, B., Kapon, M., Marin, F., Adir, N., Zolotoyabko, E., 2007. Protein-induced, previously unidentified twin form of calcite. Proc. Natl. Acad. Sci. U.S.A. 104 7337-7341.

Politi, Y., Mahamid, J., Goldberg, H., Weiner, S., Addadi, L., 2007. Asprich mollusk shell protein: in vitro experiments aimed at elucidating function in $\mathrm{CaCO}_{3}$ crystallization. CrystEngComm 9, 1171-1177.

Radha, A.V., Forbes, T., Killian, C.E., Gilbert, P.U.P.A., Navrotsky, A., 2010. Transformation and crystallization energetics of synthetic and biogenic amorphous calcium carbonate. PNAS 107, 16438-16443.

Ren, R., Mayer, B.J., Cicchetti, P., Baltimore, D., 1993. Identification of a ten-amino acid proline-rich SH3 binding site. Science 259, 1157-1161.

Sambrook, J., Fritch, E.F. Maniatis, T., 1989. Molecular Cloning: A Laboratory Manual. Cold Spring Harbor Laboratory Press, Cold Spring Harbor, New York.

Schuck, P., 2000. Size-distribution analysis of macromolecules by sedimentation velocity ultracentrifugation and lamm equation modeling. Biophys. J. 78, 1606-1619.

Schultz, J., Milpetz, F., Bork, P., Ponting, C.P., 1998. SMART, a simple modular architecture research tool: Identification of signaling domains. Proc. Natl. Acad. Sci. U.S.A. 95, 5857-5864

Sel, O., Radha, A.V., Dideriksen, K., Navrotsky, A., 2012. Amorphous iron (II) carbonate: Crystallization energetics and comparison to other carbonte minerals related to $\mathrm{CO}_{2}$ sequestration. Geoch. et Cosmo. Acta 87, 61-68.

Seto, J., Ma, Y., Davis, S.A., Meldrum, F., Gourrier, A., et al., 2012. Structure-property relationships of a biological mesocrystal in the adult sea urchin spine. PNAS 109, 7120-7126.

Silva, J.R., 2000. The onset of phagocytosis and identity in the embryo of Lytechinus variegatus. Dev. Comp. Immunol. 24, 733-739.

Smith, L.C., 2005. Host Responses to Bacteria: Innate Immunity in Invertebrates. Cambridge University Press.

Sucov, H.M., Benson, S., Robinson, J.J., Britten, R.J., Wilt, F.H., et al., 1987. A lineagespecific gene encoding a major matrix protein of the sea urchin embryo spicule: II. Structure of the gene and derviced sequence of the protein. Dev. Biol. 120,507-519.

Tsumoto, K., Umetsu, M., Kumagai, I., Ejima, D., Philo, J.S., et al., 2004. Role of arginine in protein refolding, solubilization, and purification. Biotechnol. Prog. 20, 1301-1308.

Uversky, V.N., 2002. Natively unfolded proteins: a point where biology waits for physics. Protein Sci. 11, 739-756.

Uversky, V.N., Gillespie, J.R., Fink, A.L., 2000. Why are "natively unfolded" proteins unstructured under physiologic conditions? Proteins 41, 415-427.

Uversky, V.N., Oldfield, C.J., Dunker, A.K., 2008. Intrinsically disordered proteins in human diseases: introducing the D2 concept. Annu. Rev. Biophys. 37, 215-246.

Verch, A., Gebauer, D., Antonietti, M., Cölfen, H., 2011. How to control the scaling of $\mathrm{CaCO}_{3}$ : a "fingerprinting technique" to classify additives. Phys. Chem. Chem. Phys. 13, 16811-16820.

Wang, X., Li, Y., 2002. Selected-control hydrothermal synthesis of alpha- and beta$\mathrm{MnO}_{2}$ single crystal nanowires. J. Am. Chem. Soc. 124, 2880-2881.

Wang, X., Sun, H., Xia, Y., Chen, C., Xu, H., et al., 2009. Lysozyme mediated calcium carbonate mineralization. J. Colloid Interface Sci. 332, 96-103.

Weiner, S., Wagner, H.D., 1998. The material bone: structure-mechanical function relationships. Annu. Rev. Mat. Sci. 28, 271-298.

Wilt, F.H., Killian, C.E., 2008. Molecular aspects of biomineralization of the echinoderm endoskeleton. Chem. Rev. 108, 4463-4474.

Xiang, J., Cao, H., Warner, J.H., Watt, A.R., 2008. Crystallization and self-assembly of calcium carbonate architectures. Cryst. Growth Des. 8, 4583-4588.

Xu, G., Evans, J.S., 1999. Model peptide studies of sequence repeats derived from the intracrystalline biomineralization protein, SM50. I. GVGGR and GMGGQ repeats. Biopolymers 49, 303-312.

Yang, Z.R., Thomson, R., McMeil, P., Esnouf, R.M., 2005. RONN: the bio-basis function neural network technique applied to the detection of natively disordered regions in proteins. Bioinformatics 21, 3369-3376.

Zhang, B., Xu, G., Evans, J.S., 2000. Model peptide studies of sequence repeats derived from the intracrystalline biomineralization protein, SM50. II. Pro,Asnrich tandem repeats. Biopolymers 54, 464-475. 